\title{
The possible benefits of reduced errors in the motor skills acquisition of children
}

\author{
Catherine M Capio ${ }^{1,2^{*}}$, Cindy HP Sit ${ }^{1,3}$, Bruce Abernethy ${ }^{1,4}$ and Rich SW Masters ${ }^{1}$
}

\begin{abstract}
An implicit approach to motor learning suggests that relatively complex movement skills may be better acquired in environments that constrain errors during the initial stages of practice. This current concept paper proposes that reducing the number of errors committed during motor learning leads to stable performance when attention demands are increased by concurrent cognitive tasks. While it appears that this approach to practice may be beneficial for motor learning, further studies are needed to both confirm this advantage and better understand the underlying mechanisms. An approach involving error minimization during early learning may have important applications in paediatric rehabilitation.
\end{abstract}

Keywords: Motor learning, Children, Rehabilitation

\section{Background}

Motor learning is the process of acquiring movement skills [1]. Conventional (explicit) theories posit that motor skills are initially learned explicitly through cognitive processes that generate declarative knowledge [2]. Such knowledge is made up of information that learners can describe verbally [3], and includes rules for the execution of the desired movement [4]. With increasing proficiency, movement skills become automated and performance becomes implicit, such that the declarative knowledge becomes inaccessible or unnecessary for movement control [5]. Masters [6] developed an alternative, implicit motor learning approach, in which movements are acquired without early dependence on working memory; thereby possibly bypassing the declarative stage that is characteristic of early explicit learning [7].

While there is considerable evidence to support the efficacy of an implicit motor learning approach, the bulk of the evidence comes from studies of adults. There is little evidence derived from children, whose information processing and cognitive abilities are still undergoing maturation [8]. As a consequence, the generalisability of implicit motor learning principles to children is unclear

\footnotetext{
* Correspondence: ccapio08@hku.hk

${ }^{1}$ Institute of Human Performance, University of Hong Kong Pokfulam Road, Hong Kong, Hong Kong SAR

Full list of author information is available at the end of the article
}

[9]. An understanding of children's movement skills learning is particularly important because engagement in motor activity is a prerequisite for development of the motor skills that are fundamental to functional tasks, school participation, and games and recreation [8] in later years of life. This paper aims to briefly review evidence from recent studies that have examined implicit motor learning in children using an errorless learning paradigm $[10,11]$ and to explore the theoretical basis of implicit motor learning in children.

\section{Errors in motor learning}

Whether the experience of errors during motor learning is a desirable component or not is a subject of debate. One view is that skill learning benefits from mistakes [12], whereas another view is that the formation of correct motor programs is delayed by the production of errors [13]. Recent research suggests that reducing errors during the early stages of motor learning is beneficial when the task involves complex, functional skills, such as skiing [14] or golf putting [4].

Maxwell and colleagues [4] proposed that errorless learning paradigms should constrain the environment to minimize the amount of errors that are committed, thereby reducing the need to test alternative movement solutions to correct errors. They showed that errorless learning resulted in motor learning that was largely implicit or non-conscious, with low accrual, or 
awareness, of declarative knowledge about the skill. Task performance was also found to be robust in the presence of a secondary cognitive task. Subsequent studies have shown that reduction of errors in the early stages of motor learning resulted in skills that were stable against physiological fatigue, were retained longer [15], and yielded superior performance [16].

\section{Errorless learning paradigm in children}

The decreased cognitive demands associated with reduced commission of errors, suggests that children, whose cognitive resources are still in development, may gain particular benefit from an errorless approach to motor learning. Maxwell, Masters and Hammond [11] first explored this possibility in a study involving children who learned golf putting in either an errorless or error-strewn learning environment. For children in errorless learning conditions, golf putting distances were incrementally increased such that the participants began with an easy task, which gradually became more difficult. In contrast, children in error-strewn conditions practiced initially with a difficult task (far distance), which was incrementally decreased. Skills learnt via errorless learning were found to be unaffected by performing a concurrent cognitive task that demanded additional attention resources. Maxwell et al. [11] also classified the children as either having high or low motor abilities, and their study provided some evidence to suggest that reducing practice errors was beneficial particularly for children with lower motor abilities.

As is characteristic of many motor learning studies, the initial evidence supporting the errorless learning approach in motor learning for children was based on a laboratory experiment. Motivated by the need for a more applied investigation, a field-based study by Capio et al. [10] utilized this learning paradigm to examine the learning of a fundamental movement skill by children in a primary school setting. Overhand throwing was practised in either an errorless or error-strewn learning environment, within the context of physical education lessons. Children who learned overhand throwing with an approach that generated fewer errors were found to achieve superior movement patterns and throwing accuracy relative to those who practised in an error-strewn environment. Additionally, children who learned overhand throwing with few errors showed stable performance while engaged in a secondary cognitive task of counting backwards. This observation was consistent with findings of implicit motor learning investigations in adults [2]. Similar to the initial study by Maxwell et al. [11], the children were also grouped according to their abilities prior to practice (high, medium, low ability). Again, those in the low ability group were found to benefit most from the errorless learning approach. This field-based study therefore confirmed that the errorless learning paradigm is beneficial as well as feasible in a school setting.

Children of lower abilities, such as those with intellectual disabilities (ID), also appear to benefit from motor learning with reduced practice errors. Children with ID have less proficient movement skills, associated with their impaired cognitive processing abilities [17]. In a recent study [18] overhand throwing practice was incorporated in the adapted PE lessons of children with mild intellectual disability. Results showed that while all participants achieved gains in throwing movement pattern and throwing accuracy, those who practised in an errorless learning environment were found to have greater improvements than those who practised in an errorstrewn condition. Moreover, those children with ID who experienced fewer practice errors were capable of effective overhand throwing while performing a secondary cognitive task.

\section{Discussion}

Motor learning approaches for children need to accommodate their evolving cognitive abilities. Younger children have been found to approach information processing differently, such that they tend to rely more on visual codes initially and learn to use verbal labels as they get older [19]. Moreover, while the initial declarative stage that is characteristic of explicit motor learning has an associated verbal monitoring process, language ability develops relatively later than movement skills like walking [20]. As the implicit motor learning approach purports to skip the initial declarative stage of learning, developmental changes may partially explain why this approach seems to benefit children. It appears that by reducing the number of practice errors in the early stages of learning, cognitive processing load during movement skills performance is reduced such that the acquired skills are less susceptible to disruption from secondary cognitive tasks [10]. However, it must be noted that further verification is needed to establish whether the skills learnt in the errorless learning paradigm are indeed implicit. Nevertheless, despite the absence of a measure of declarative knowledge accumulation, the apparent benefits associated with errorless learning environments may provide an important basis for further work in implicit motor learning in children.

Reber [21] used an evolutionary framework to argue that implicit learning processes constitute an older cognitive system than explicit learning processes. Consequently, implicit learning should be largely unaffected by either age or intelligence (IQ). Such an evolutionary perspective offers an explanation for why the patterns observed in implicit learning among adult learners have been replicated in children despite different cognitive 
processing abilities. Consistent with the findings of the recent studies $[10,11,18]$, a lack of sensitivity to both age [22] and IQ [23] has also previously been demonstrated for implicit motor learning in simpler sensorimotor tasks.

Alternative motor learning perspectives may also explain the apparent effectiveness of the errorless learning approach in children. Developmental principles of motor development have been influenced by the dynamical systems perspective [24], for example, with movement viewed as a consequence of dynamic interactions between internal (e.g., neurological structure) and external constraints (e.g., feedback from the environment). If the environmental constraints are consistent, stable movement patterns develop [25]. It may be that in restricting practice errors, environmental constraints become more consistent, which facilitates stable movement patterns. What remains to be determined, however, is whether, and to what degree, emphasizing errorless learning may restrict the opportunities to fully explore the boundary conditions under which different movement patterns can (and cannot) be used successfully. This aspect relates to the potential limitation in the development of movement adaptability.

The ecological perspective on motor skills development in children emphasizes the role of the environment in promoting developmental change [26], and in the eventual development of effective movement skills. While the environmental constraints that are manipulated in motor learning strategies are often physical in nature (e.g., equipment, setting), social aspects of the environment are particularly relevant for young learners whose performances are strongly influenced by their peers [27]. For instance, preschool children who underwent training in object control skills were found to have improved perceptions of their physical competence when the learning environment accommodated their desired levels of difficulty $[28,29]$. It has been suggested that the opportunities children have to experience success, contribute to their early self-judgment of their abilities and capabilities [30,31], encouraging subsequent performance of the learned skills. This socio-affective aspect of motor skills acquisition may also be a factor that leads to the possible benefits of errorless learning in children.

\section{Implications}

Rehabilitation programs for children include multi-disciplinary approaches that foster capacities and social participation [32]. In the framework of the International Classification of Function, Disability, and Health (ICF), a holistic perspective on a child's status includes not only the movement performance itself, but also the context in which it is applied in the real world (e.g., school, playground) [33]. Such considerations raise issues related to diverse and multiple stimuli and performance pressures that are present in a child's daily environment. Movement skills that will remain stable in the face of such challenges in the environment are thus desirable for children. A reduction of practice errors during learning may therefore be useful in planning rehabilitation and sports programs for children.

The findings that were summarized in this paper also signal the need to conduct further research to establish theoretical and practical evidence. For instance, future work is needed to examine if benefits persist across different developmental conditions such as cerebral palsy, Down syndrome, or developmental coordination disorder. Furthermore, the impact of an errorless learning approach on movement adaptability (as opposed to consistency and stability) has yet to be examined. Ultimately, the mechanisms underpinning the effects of errorless learning in motor skills acquisition in children clearly require further exploration and understanding.

\section{Author details \\ ${ }^{1}$ Institute of Human Performance, University of Hong Kong Pokfulam Road, Hong Kong, Hong Kong SAR. 'Faculty of Kinesiology and Rehabilitation Sciences, Katholieke Universiteit Leuven Tervusevestraat, Heverleee 3001, Belgium. 'Department of Sports Science and Physical Education, Chinese University of Hong Kong Kwok Sports Building, Shatin NT, Hong Kong SAR. ${ }^{4}$ School of Human Movement Studies, University of Queensland Blair Drive, Brisbane Queensland 4072, Australia.}

\section{Authors' contributions}

CMC developed the main structure of the current concept paper and carried out two of the studies that were focal reference points in the manuscript. CHPS conceived of the current concept paper and contributed to the structure and content of the manuscript. BA contributed to structuring and refining the critical points of argument of the current concept. RSWM developed the main concept being discussed through numerous studies, and participated in all the key reference studies of the current concept. All the authors contributed to the writing, and have read and approved the final version of the manuscript.

\section{Competing interests}

The authors declare that they have no competing interests.

Received: 27 September 2011 Accepted: 9 January 2012 Published: 9 January 2012

\section{References}

1. Maxwell JP, Masters RSW: The explicit consequences of error in motor learning. In Sport and Exercise Psychology Research Advances. Edited by: Simmons MP, Foster LA. Hauppauge, NY: Nova Science Publishers, Inc; 2009:111-133.

2. Steenbergen B, van der Kamp J, Verneau M, Jongbloed-Pereboom $M$, Masters RSW: Implicit and explicit learning: applications from basic research to sports for individuals with impaired movement dynamics. Disabil Rehabil 2010, 32:1509-1516.

3. Magill RA: Knowledge is more than we can talk about: Implicit learning in motor skill acquisition. Res Q Exerc Sport 1998, 69:104-110.

4. Maxwell JP, Masters RSW, Kerr E, Weedon E: The implicit benefit of learning without errors. Q J Exp Psychol-A 2001, 54:1049-1068.

5. Fitts P, Posner M: Human Performance Belmont, CA: Brooks/Cole; 1976. 
6. Masters RSW: Knowledge, Knerves and Know-How - the Role of Explicit Versus Implicit Knowledge in the Breakdown of a Complex Motor Skill under Pressure. Brit J Psychol 1992, 83:343-358.

7. Masters RSW, Maxwell JP: Implicit motor learning, reinvestment and movement disruption: What you don't know won't hurt you? In Skill acquisition in sport: Research, theory and practice. Edited by: Williams AM, Hodges NJ. London: Routledge; 2004:207-228.

8. Abernethy AB, Hanrahan SJ, Kippers V, MacKinnon L, Pandy M: Biophysical Foundations of Human Movement. 2 edition. Illinois: Human Kinetics; 2005.

9. Sullivan K, Kantak SS, Burtner PA: Motor learning in children: feedback effects on skill acquisition. Phys Ther 2008, 88:720-732.

10. Capio CM, Poolton JM, Sit CHP, Holmstrom M, Masters RSW: Reducing errors benefits the field-based learning of a fundamental movement skill in children. Scand J Med Sci Sports 2011, doi: 10.1111/j.16000838.2011.01368.x.

11. Maxwell JP, Masters RSW, Hammond J: Interactions between implicit/ explicit learning and fundamental movement ability in children. 13th European College of Sports Science Annual Congress; 9-12 July 2008; Estoril, Portugal 2008.

12. Ohlsson S: Learning from performance errors. Psychol Rev 1996, 103:241-262.

13. McClelland JL, Thomas AG, McCandliss BD, Fiez JA: Understanding failures of learning: Hebbian learning, competition for representational space, and some preliminary experimental data. Prog Brain Res 1999, 121:75-80.

14. Wulf $\mathrm{G}$, Shea $\mathrm{CH}$, Whitacre CA: Physical-guidance benefits in learning a complex motor skill. J Mot Behav 1998, 30:367-380.

15. Poolton JM, Masters RSW, Maxwell JP: Passing thoughts on the evolutionary stability of implicit motor behaviour: Performance retention under physiological fatigue. Conscious Cogn 2007, 16:456-468.

16. Zhu FF, Poolton JM, Wilson MR, Maxwell JP, Masters RSW: Neural coactivation as a yardstick of implicit motor learning and the propensity for conscious control of movement. Biol Psychol 2011, 87:66-73.

17. Westendorp M, Houwen S, Hartman E, Visscher C: Are gross motor skills and sports participation related in children with intellectual disabilities? Res Dev Disabil 2011, 32:1147-1153.

18. Capio CM, Sit CHP, Poolton JM, Abernethy B, Masters RSW: Training a fundamental movement skill in children with disabilities. 18th International Symposium on Adapted Physical Activity; 4-8 July 2011; Paris, France 2011

19. Alloway TP, Gathercole SE, Pickering SJ: Verbal and visuospatial short-term and working memory in children: Are they separable? Child Dev 2006 77:1698-1716.

20. van der Kamp J, Oudejans R, Savelsbergh G: The development and learning of the visual control of movement: An ecological perspective. Infant Behav Dev 2003, 26:495-515.

21. Reber AS: The cognitive unconscious: An evolutionary perspective. Conscious Cogn 1992, 1:93-133.

22. Vinter A, Perruchet P: Implicit learning in children is not related to age: Evidence from drawing behavior. Child Dev 2000, 71:1223-1240.

23. Vinter A, Detable C: Implicit learning in children and adolescents with mental retardation. Am J Mental Retard 2003, 108:94-107.

24. Thelen E, Smith LB: A dynamic systems approach to the development of cognition and action Boston: MIT Press; 1994.

25. Renshaw I, Davids KW, Shuttleworth R, Chow JY: Insights from ecological psychology and dynamical systems theory can underpin a philosophy of coaching. Int I Sport Psychol 2009, 40:540-602.

26. Thelen E: Motor development as foundation and future of developmental psychology. Int J Behav Dev 2000, 24:385-397.

27. Chow JY, Davids K, Button C, Shuttleworth R, Renshaw I, Araujo D: The role of Nonlinear pedagogy in physical education. Rev Educ Res 2007, 77:251-278.

28. Robinson LE, Goodway JD: Instructional climates in preschool children who are at-risk. Part I: Object-control skill development. Res Q Exerc Sport 2009, 80:533-542.

29. Robinson LE, Rudisill ME, Goodway JD: Instructional climates in preschool children who are at-risk. Part II: Perceived physical competence. Res $Q$ Exerc Sport 2009, 80:543-551.

30. Harter S: Effectance motivation reconsidered: Toward a developmental model. Hum Dev 1978, 21:34-64.
31. Harter S: A model of intrinsic mastery motivation in children: individual differences and developmental change. In Minnesota Symposia on Child Psychology. Volume 14. Hillsdale NJ: Erlbaum; 1981.

32. Camden C, Tétreault S, Swaine B: Rehabilitation for children - How is it different from rehabilitation for adults? In International Encyclopedia of Rehabilitation. Edited by: Stone JH, Blouin M. Buffalo, NY: Center for International Rehabilitation Research Information and Exchange (CIRRIE); 2011:

33. WHO: International classification of functioning, disability, and health: children and youth version: ICF-CY Geneva: World Healthh Organization; 2007.

doi:10.1186/1758-2555-4-1

Cite this article as: Capio et al: The possible benefits of reduced errors in the motor skills acquisition of children. Sports Medicine, Arthroscopy, Rehabilitation, Therapy \& Technology 2012 4:1.

\section{Submit your next manuscript to BioMed Central and take full advantage of:}

- Convenient online submission

- Thorough peer review

- No space constraints or color figure charges

- Immediate publication on acceptance

- Inclusion in PubMed, CAS, Scopus and Google Scholar

- Research which is freely available for redistribution

Submit your manuscript at www.biomedcentral.com/submit
Ciomed Central 